\title{
Systems Biology Model of Cerebral Oxygen Delivery and Metabolism During Therapeutic Hypothermia: Application to the Piglet Model
}

\author{
Joshua Russell-Buckland, P. Kaynezhad, S. Mitra, \\ G. Bale, C. Bauer, I. Lingam, C. Meehan, \\ A. Avdic-Belltheus, K. Martinello, A. Bainbridge, \\ N. J. Robertson, and I. Tachtsidis
}

\begin{abstract}
Hypoxic ischaemic encephalopathy (HIE) is a significant cause of death and disability. Therapeutic hypothermia $(\mathrm{TH})$ is the only available standard of treatment, but $45-55 \%$ of cases still result in death or neurodevelopmental disability following TH. This work has focussed on developing a new brain tissue physiology and biochemistry systems biology model that includes temperature effects, as well as a Bayesian framework for analysis of model parameter estimation. Through this, we can simulate the effects of temperature on brain tissue oxygen delivery and metabolism, as well as analyse clinical and experimental data to identify mechanisms to explain differ-
\end{abstract}

J. Russell-Buckland $(\bowtie) \cdot$ P. Kaynezhad $\cdot$ G. Bale

C. Bauer $\cdot$ I. Tachtsidis

Department of Medical Physics and Biomedical

Engineering, University College London,

London, UK

e-mail: j.russell-buckland.15@ucl.ac.uk

S. Mitra - I. Lingam - C. Meehan - A. Avdic-Belltheus

K. Martinello $\cdot$ N. J. Robertson

Institute for Women's Health, University College

London, London, UK

A. Bainbridge

Department of Medical Physics and Biomedical

Engineering, University College London Hospital,

London, UK ing behaviour and outcome. Presented here is an application of the model to data from two piglets treated with $\mathrm{TH}$ following hypoxicischaemic injury showing different responses and outcome following treatment. We identify the main mechanism for this difference as the $\mathrm{Q}_{10}$ temperature coefficient for metabolic reactions, with the severely injured piglet having a median posterior value of 0.133 as opposed to the mild injury value of 5.48. This work demonstrates the use of systems biology models to investigate underlying mechanisms behind the varying response to hypothermic treatment.

\section{Keywords}

Broadband NIRS $\cdot$ Hypothermia $\cdot$ Systems biology $\cdot$ Piglet $\cdot$ Brain

\subsection{Introduction}

Hypoxic-ischaemic encephalopathy (HIE) is a significant cause of death and morbidity amongst neonates with around 700,000 deaths attributed to HIE alone annually [1]. Following neonatal HI injury, infants are treated with therapeutic hypothermia (TH) at a body temperature of $33.5^{\circ} \mathrm{C}$ 
[2]. However, $45-55 \%$ of cases treated with hypothermia end with death or moderate to severe neurodevelopmental disability [1, 3]. During hypothermia, a close neuromonitoring is in place combining clinical electroencephalography (EEG) [4] and broadband NIRS [2, 5] as a research tool in the neonatal unit in University College London Hospital (UCLH). After completion of $\mathrm{TH}$, infants undergo magnetic resonance imaging (MRI) and spectroscopy (MRS) [6]. The collected multimodal data has the potential to provide not only diagnostic and prognostic information but also insights on the mechanisms of the injury.

Our approach to analysis of this multimodal data has been multifaceted, with one key facet being the development and application of a physiology-informed "mathematical model" of the cerebral circulation under a systems biology approach, which is specially designed for the interpretation of bNIRS signals [7-12].

The first model BRAINCIRC was developed in 2005 [7]. This was later simplified and extended to include metabolism in 2008 via the BrainSignals model [8]. This was used to develop the BrainPiglet model [9], with the piglet being a common clinical model of human neonates. BrainPiglet was extended and used to investigate the effect of hypoxic ischaemia in the piglet model in the BrainPigletHI model [10]. Separate to the piglet models, BrainSignals was simplified further in the BrainSignals Revisited (BSRV) model to improve run time [11]. BSRV was extended to include extracerebral blood flow in BSX and looked at the confounding effects of the scalp on measurements [12]. Recently, significant work has been undertaken in developing the "BP Hypothermia" model (BPH1) which extended the BrainPiglet HI model to include temperature as an input [13]. This is needed to properly interpret data collected during therapeutic hypothermia. For example, it has been observed that both cerebral metabolic rate of oxygen $\left(\mathrm{CMRO}_{2}\right)$ and cerebral blood flow $(\mathrm{CBF})$ in piglets decrease with reduced body temperature [14]. For reliable inferences to be made using systems biology models, they must be able to simulate this behaviour.
We present here an extended version of this model, BP Hypothermia 2 (BPH2), able to incorporate the effect of temperature separately for both metabolic and haemodynamic processes and reactions. This model is then validated against data collected from piglets undergoing TH following HIE.

\subsection{Methods}

$\mathrm{BPH} 2$ follows the same form as the original BP Hypothermia model [14], incorporating the effect of temperature by adapting work by Orlowski et al. [15]. Reaction rates, Michaelis-Menten rate constants and diffusion rates are modified by the quantities

$$
\begin{aligned}
& k_{i, \text { new }}=k_{i, \text { previous }} \times Q_{10, \text { haemo }}^{\left(T_{\text {new }}-T_{\text {prexious }}\right)} / 10 \\
& k_{j, \text { new }}=k_{j, \text { previous }} \times Q_{10, \text { met }}^{\left(T_{\text {new }}-T_{\text {previous }}\right)} / 10
\end{aligned}
$$

where $Q_{10 \text {, haemo }}$ is the $Q_{10}$ coefficient for haemodynamic reactions, $Q_{10 \text {, met }}$ is the $Q_{10}$ coefficient for metabolic reactions, $k_{i, *}$ is the reaction rate for the $i$ th haemodynamic reaction and $k_{j, *}$ is the reaction rate for the $j$ th metabolic reaction at temperatures $T_{\text {new }}$ and $T_{\text {previous. }} Q_{10}$ is the temperature coefficient, defined as the ratio of reaction rates measured for the same reaction at two temperatures $10{ }^{\circ} \mathrm{C}$ apart. $0<Q_{10}<1$ indicates that decreasing temperature increases the reaction rate, whilst $Q_{10}>1$ indicates that decreasing temperature decreases the reaction rate. Figure 5.1 outlines the structure of this model.

This model was then used to analyse data from two piglets, as shown in Fig. 5.2. Data was collected as per [16], with the piglets' common carotid arteries occluded for a period of around 25 minutes. Following HI, the piglets were treated with $\mathrm{TH}$ at $33.5{ }^{\circ} \mathrm{C} . \mathrm{HbO}_{2}, \mathrm{HHb}$ and CCO data was collected via bNIRS, whilst the thalamic lactate/N-acetyl-aspartate (Lac/NAA) ratio was measured at 24 hours using proton MRS. Piglet LWP475 suffered a mild injury with a 10-minute CCO recovery fraction of 


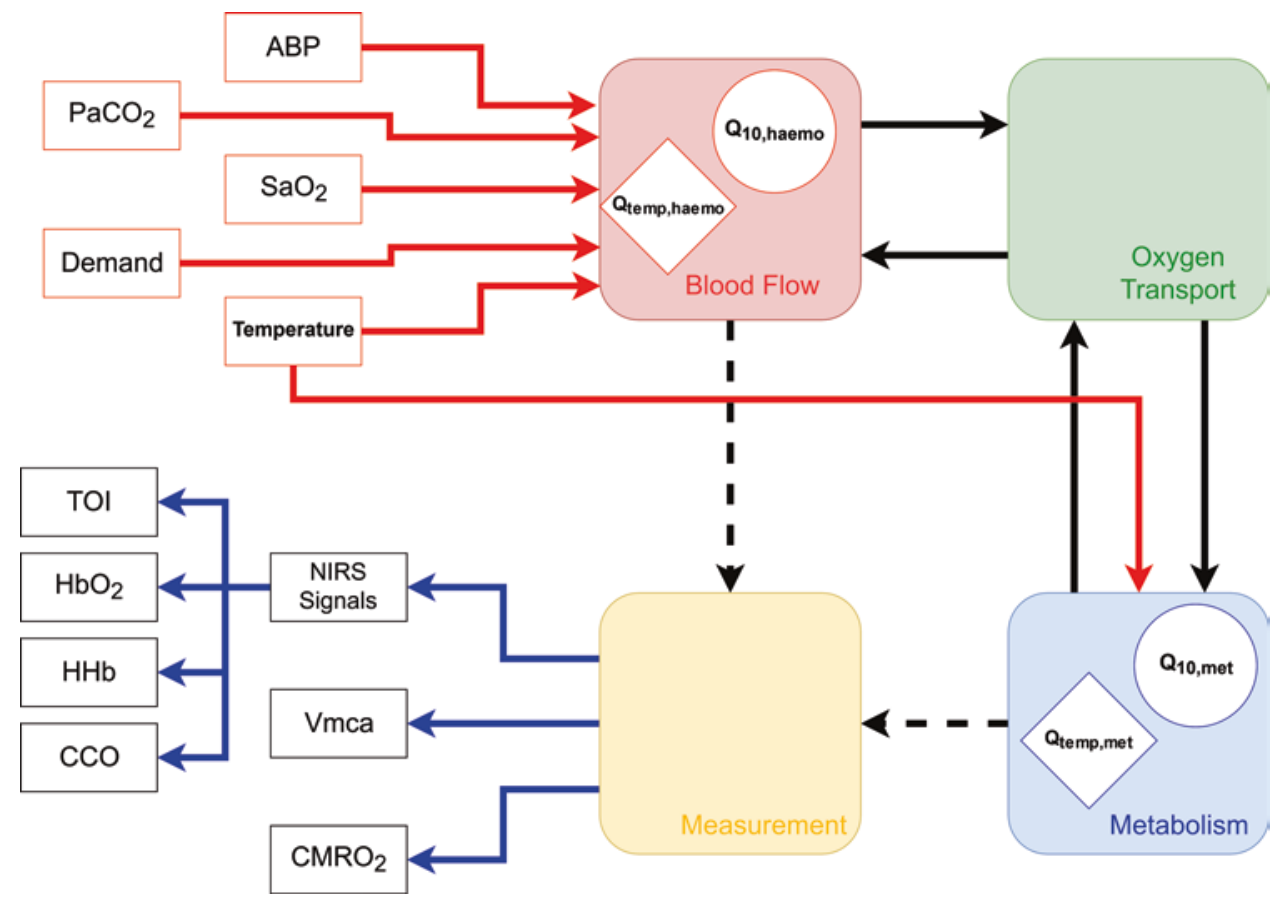

Fig. 5.1 General structure of the BrainPiglet hypothermia 2 model. Model inputs, arterial blood pressure (ABP), arterial oxygen saturation $\left(\mathrm{SaO}_{2}\right)$, partial pressure of $\mathrm{CO}_{2}$ $\left(\mathrm{PaCO}_{2}\right)$ and demand, and outputs, concentrations of oxyhaemoglobin $\left(\mathrm{HbO}_{2}\right)$, deoxyhaemoglobin $(\mathrm{HHb})$ and cytochrome- $c$-oxidase $(\mathrm{CCO})$, tissue oxygenation index (TOI), middle cerebral artery velocity $\left(V_{\mathrm{mca}}\right)$ and cerebral

$122 \%$ and a Lac/NAA ratio of 0.21 (Lac/ NAA $\geq 0.39[6]$ is associated with a poor outcome). Piglet LWP479 suffered a severe injury with a 10 -minute $\mathrm{CCO}$ recovery fraction of $69 \%$ and a 24-hour Lac/NAA ratio of 1.03. Both piglets received TH with piglet LWP475 responding typically, as per [13], with increased $\mathrm{HbO}_{2}$, decreased $\mathrm{HHb}$ and decreased $\mathrm{CCO}$, whilst piglet LWP479 responded atypically with an "inverted" response in the bNIRS signals. Model analysis was performed using the BayesCMD framework [17].

Before performing model fitting, it is necessary to reduce the model down to manageable number of parameters. This is done using sensitivity analysis (SA) in order to identify parameters that control the majority of the behaviour metabolic rate of oxygen $\left(\mathrm{CMRO}_{2}\right)$, are shown, as well as each of the four sub-models and the general relations between each. New additions are shown in bold. Temperature is added as an input to the model. Parameter $Q_{10 \text {, met }}$ and temporary variable $Q_{\text {temp, met }}$ are added to the metabolic compartment, and parameter $Q_{10}$, haemo and temporary variable $Q_{\text {temp, haemo }}$ are added to the blood flow compartment

we are attempting to simulate. We used the Morris method, summarising model output by the normalised root-mean-square error (NRMSE) between simulation and measured data. This was performed twice per model, once substituting the NRMSE value of failed runs with zero and once replacing it by 10,000,000. This was done to try and find a balance between including sensitive parameters that may produce failed runs and only selecting parameters that overwhelmingly cause failed runs. Failed runs should not be ignored completely as the reason a run fails is likely to be due to an invalid value for a highly sensitive parameter. Parameter count was reduced from an original count of 234 to a fitted count of 11 , with this parameters shown in Table 5.1. 
a)

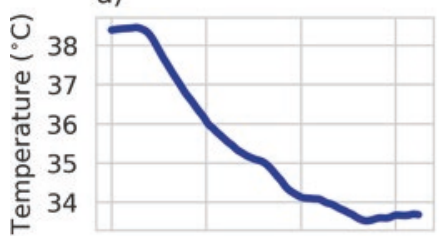

d)

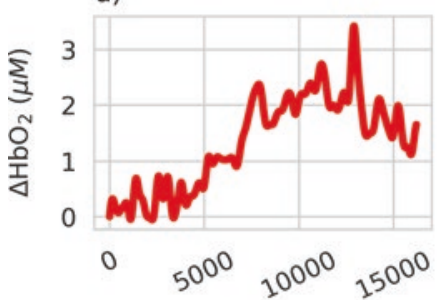

g)

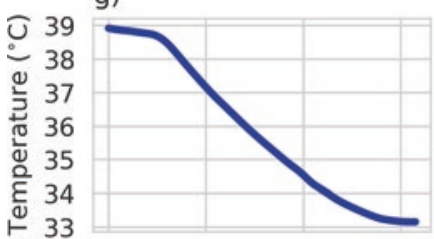

j)

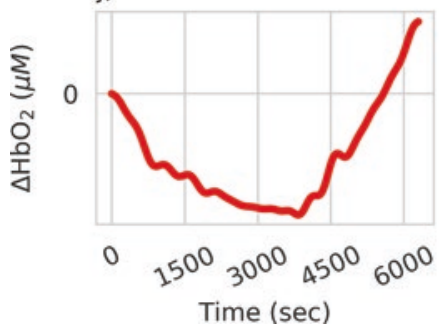

b)

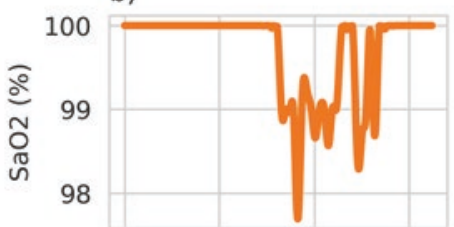

e)

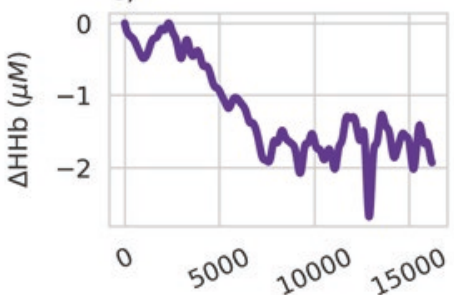

h)

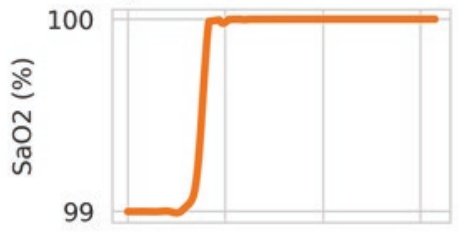

k)

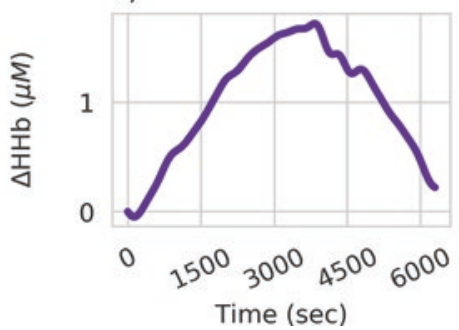

c)

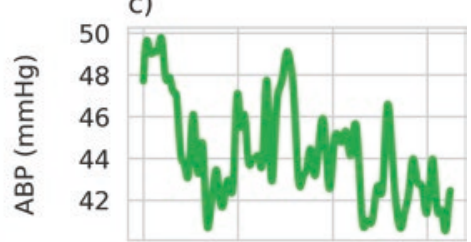

f)

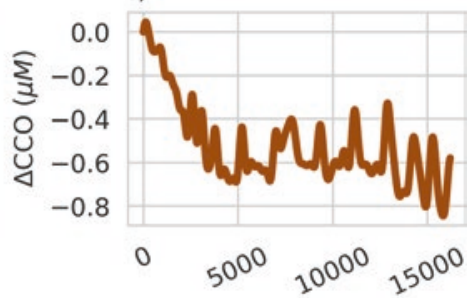

i)

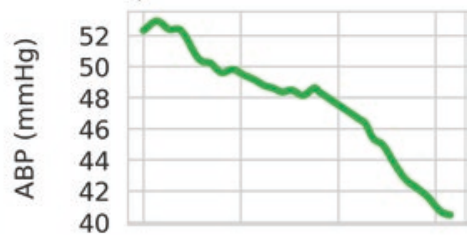

I)

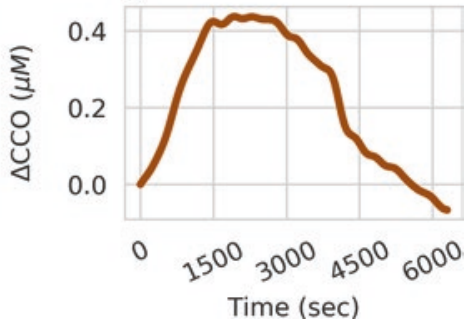

Fig. 5.2 Data for piglets LWP475 (a-f) and LWP479 (g-l). Measured data for piglets LWP475 and LWP479, showing the piglet response to hypothermia across measurable quantities

\subsection{Result}

Following this, posterior parameter distribution fitting was performed using approximate Bayesian computation via a rejection algorithm with a total of 50,000,000 samples. Each parameter was given an uninformative uniform prior distribution. The top $0.01 \%$ of parameter samples, based on NRMSE, were used to generate posterior distributions for each piglet giving a posterior of 5000 samples. These are shown in Fig. 5.3 with piglet LWP475 shown in blue and piglet LWP479 in orange. A distinct difference between the parameter spaces of the two piglets is clearly visible for

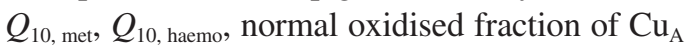
$\left(a_{\text {frac, } n}\right)$ and the normal total concentration of
$\mathrm{HbO}_{2}$ binding sites in blood $\left(X_{\mathrm{tot}, n}\right)$, with $Q_{10 \text {, met }}$ showing the most obvious and potentially important disparity. For further information about $a_{\mathrm{frac}, n}$ and $X_{\text {tot, } n}$, see Table 5.1 and [10].

Figure 5.4 shows the posterior predictive distributions for each piglet generated by sampling repeatedly from the posterior distributions shown in Fig. 5.3. The posterior predictive distributions are shown in blue and include a 95\% confidence interval, whilst data is shown in green. The model simulations show good agreement with the measured data with only a small time lag between the model and data for the CCO signal in piglet LWP479. Importantly, the model can correctly reproduce the overall behaviour of the system in both piglets suggesting that the posterior distri- 


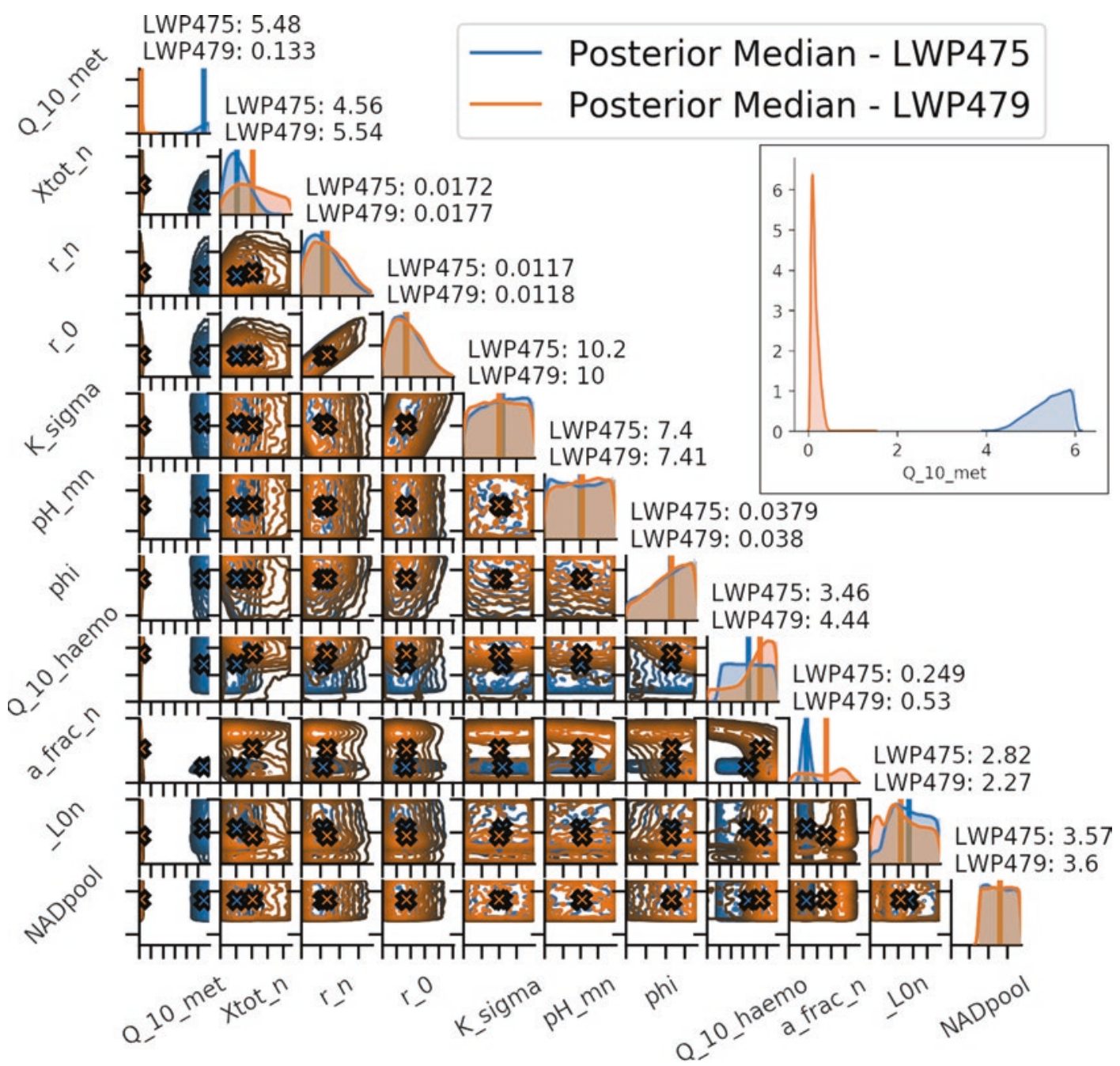

Fig. 5.3 Posterior parameter distributions. Posterior distributions of parameters with those for piglet LWP475 shown in blue and those for piglet LWP479 shown in orange. Inset are the marginal distributions for parameter

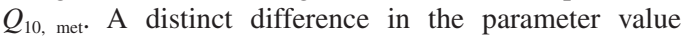

between the two piglets is clearly visible, with piglet LWP479 having a distribution of values well below 1. For more information about specific parameters, please see Table 5.1 butions produced in Fig. 5.3 are reasonably good indications of the mechanisms behind the difference in the measured responses to hypothermia.

\subsection{Discussion}

We have successfully expanded our model of hypothermia in the piglet brain to incorporate different temperature effects on metabolic and haemodynamic reactions. Additionally, this has been achieved without introducing excessive complexity into the model, adding only one new parameter as compared to the previous BPH1 model $-\boldsymbol{Q}_{10}$ is split into $\boldsymbol{Q}_{10 \text {,met }}$ and $\boldsymbol{Q}_{\mathbf{1 0} \text {,haemo }}$. This model has then been validated against data collected from two piglets suffering the same injury to differing levels of severity. Not only was this able to validate the new model but it was also able to provide some insight into the different haemodynamic and metabolic behaviour seen in both piglets. 


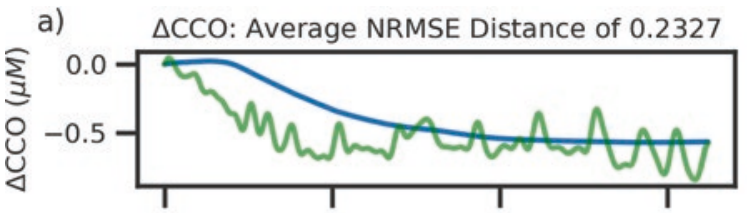

b) $\triangle$ CCO: Average NRMSE Distance of 0.4691
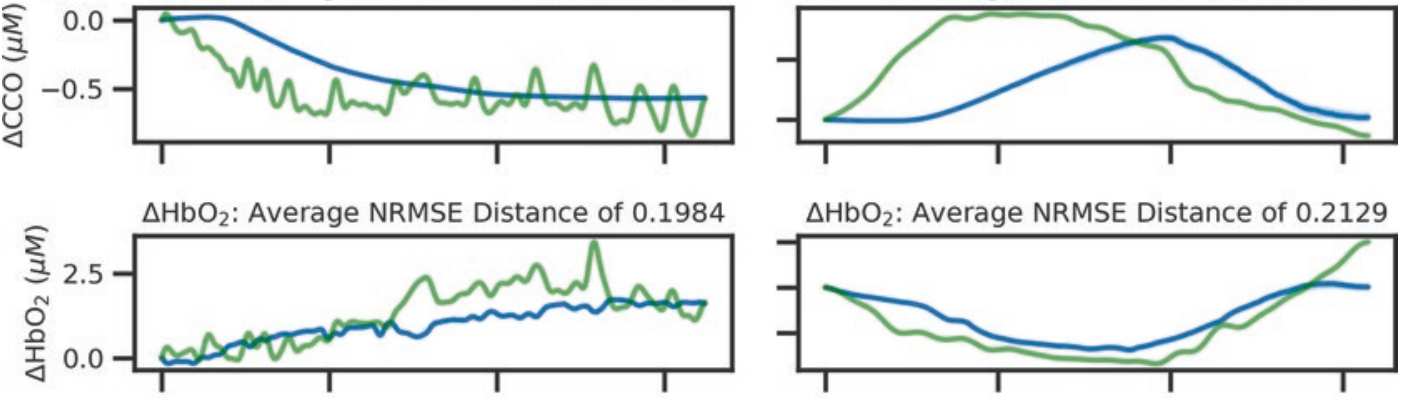

$\triangle \mathrm{HHb}$ : Average NRMSE Distance of 0.1436

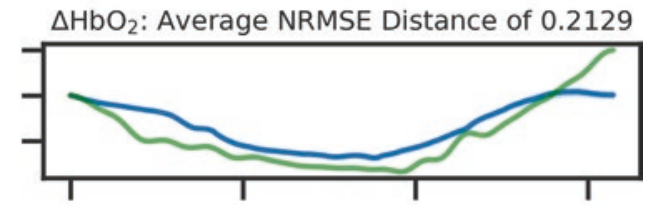

$\triangle \mathrm{HHb}$ : Average NRMSE Distance of 0.1696
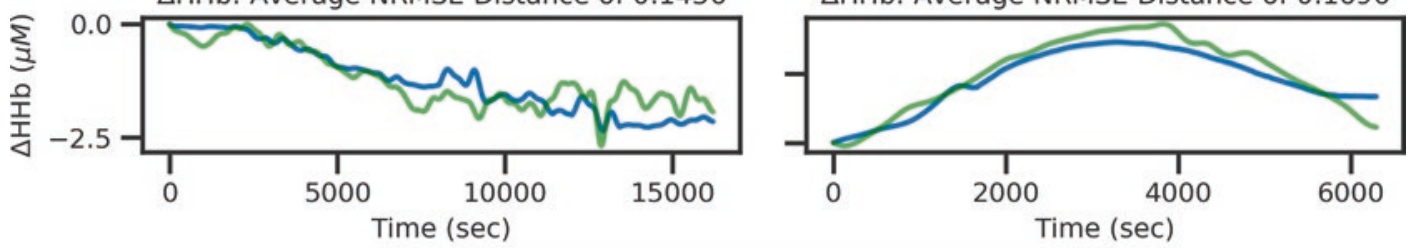

Data

Fig. 5.4 Posterior predictive distributions for piglet LWP475 (a) and LWP479 (b). The posterior predictive distributions show good agreement between model (blue)

Table 5.1 Final model parameters as selected by sensitivity analysis

\begin{tabular}{l|l|l}
\hline Symbol & Description & $\begin{array}{l}\text { Default } \\
\text { value }\end{array}$ \\
\hline $\begin{array}{l}\text { Q_10_- } \\
\text { met }\end{array}$ & $\begin{array}{l}\text { Temperature coefficient for } \\
\text { metabolic reactions }\end{array}$ & 2.23 \\
\hline $\begin{array}{l}\text { Q_10_ } \\
\text { haemo }\end{array}$ & $\begin{array}{l}\text { Temperature coefficient for } \\
\text { haemodynamic reactions }\end{array}$ & 2.23 \\
\hline Xtot_n & $\begin{array}{l}\text { Normal total haemoglobin } \\
\text { concentration }\end{array}$ & $5.4 \mathrm{mM}$ \\
\hline r_n & Normal blood vessel radius & $0.0187 \mathrm{~cm}$ \\
\hline r_0 & $\begin{array}{l}\text { Special radius in the elastic } \\
\text { tension relationship }\end{array}$ & $0.0126 \mathrm{~cm}$ \\
\hline K_sigma & $\begin{array}{l}\text { Parameter controlling } \\
\text { sensitivity of } \sigma_{\mathrm{e}} \text { to vessel } \\
\text { radius }\end{array}$ & 10 \\
\hline pH_mn & Normal mitochondrial $\mathrm{pH}$ & 7.4 \\
\hline phi & $\begin{array}{l}\text { Oxygen concentration at } \\
\text { half-maximal saturation }\end{array}$ & $0.036 \mathrm{mM}$ \\
\hline a_frac_n & $\begin{array}{l}\text { Normal oxidised fraction } \\
\text { Cu }\end{array}$ & 0.67 \\
\hline _L0n & $\begin{array}{l}\text { Normal concentration of } \\
\text { lactate in the cytoplasm } \\
\text { Total mitochondrial NAD } \\
\text { and NADH concentration }\end{array}$ & $3.0 \mathrm{mM}$ \\
\hline NADpool & $3.0 \mathrm{mM}$ \\
\hline
\end{tabular}

Piglet LWP475 suffered a mild injury, as indicated by both its typical response to hypothermia, as per [13], and its Lac/NAA ratio of 0.21. The $Q_{10 \text {,met }}$ and $Q_{10 \text {,haemo }}$ values obtained by fitting are all above 1 indicating that decreasing temperature does decrease reaction rates for both haemodynamic and metabolic reactions. In contrast, piglet LWP479 suffered a severe injury and exhibited an atypical response to hypothermia. The $\mathrm{HbO} 2, \mathrm{HHb}$ and CCO signals all produce behaviour opposite to that seen in piglet LWP475. Model analysis then showed that this is likely to be due to a breakdown in how the metabolic reactions responded to hypothermia, with $\boldsymbol{Q}_{10 \text {,met }}$ values all within a narrow distribution well below 1 , with a median value of 0.133 . Thus, for this piglet, hypothermia will increase metabolic reaction rate rather than decrease it, but haemodynamic reaction rate will react "typically", reducing with temperature. A small time lag is seen between measured data and predictive posterior distribution, which may be due to the model reduction removing a parameter nec- 
essary to control this behaviour. Improvement of the model reduction process may help with this.

Whilst it is not possible to draw clinical conclusions from these results yet, the different parameter spaces for these two piglets does potentially highlight issues with treating all HIE injuries in the same way. Findings here suggest that in certain circumstances the initial injury may impact on how the various reactions and processes respond to cooling and that this change in response may be the opposite of that desired. Further work will look at applying these methods and models to understanding data collected from human neonates that have suffered HIE.

\section{References}

1. Hassell KJ, Ezzati M, Alonso-Alconada D et al (2015) New horizons for newborn brain protection: enhancing endogenous neuroprotection. Arch Dis Child Fetal Neonatal Ed 100:F541-F552

2. Bale G, Mitra S, de Roever I et al (2019) Oxygen dependency of mitochondrial metabolism indicates outcome of newborn brain injury. J Cereb Blood Flow Metab 39(10):2035-2047

3. Gluckman P, Wyatt J, Azzopardinna D et al (2005) Selective head cooling with mild systemic hypothermia after neonatal encephalopathy: multicentre randomized trial. Lancet 365(9460):663-670

4. Murray D, Boylan GB, Ryan AC et al (2009) Early EEG findings in hypoxic-ischemic encephalopathy predict outcomes at 2 years. Pediatrics 124:e459-e467

5. Bale G, Mitra S, Meek J et al (2014) A new broadband near-infrared spectroscopy system for in-vivo measurements of cerebral cytochrome-c-oxidase changes in neonatal brain injury. Biomed Opt Express 5(10):3450-3466

6. Mitra S, Kendall GS, Bainbridge A et al (2019) Proton magnetic resonance spectroscopy lactate/N-acetylaspartate within 2 weeks of birth accurately predicts 2-year motor, cognitive and language outcomes in neonatal encephalopathy after therapeu- tic hypothermia. Arch Dis Child Fetal Neonatal Ed 104:F424-F432

7. Banaji M, Tachtsidis I, Delpy D, Baigent S (2005) A physiological model of cerebral blood flow control. Math Biosci 194(2):125-173

8. Banaji M, Mallet A, Elwell CE, Nicholls P, Cooper CE (2008) A model of brain circulation and metabolism: NIRS signal changes during physiological challenges. PLoS Comput Biol 4(11):e1000212

9. Moroz T, Banaji M, Robertson NJ, Cooper CE, Tachtsidis I (2012) Computational modelling of the piglet brain to simulate near-infrared spectroscopy and magnetic resonance spectroscopy data collected during oxygen deprivation. J R Soc Interface 9(72):1499-1509

10. Caldwell M, Moroz T, Hapuarachchi T et al (2015) Modelling blood flow and metabolism in the preclinical neonatal brain during and following hypoxic-ischaemia. PLoS One 10:e0140171

11. Caldwell M, Hapuarachchi T, Highton D et al (2015) BrainSignals revisited: simplifying a computational model of cerebral physiology. PLos One 10:e0126695

12. Caldwell M, Scholkmann F, Wolf U, Wolf M, Elwell C, Tachtsidis I (2016) Modelling confounding effects from extracerebral contamination and systemic factors on functional near-infrared spectroscopy. NeuroImage 143:91-105

13. Russell-Buckland J, Tachtsidis I (2020) Developing a model to simulate the effect of hypothermia on cerebral blood flow and metabolism. Adv Exp Med Biol 1232:299-306

14. Ehrlich MP, McCullough JN, Zhang N et al (2002) Effect of hypothermia on cerebral blood flow and metabolism in the pig. Ann Thorac Surg 73:191-197

15. Orlowski P, McConnell FK, Payne S (2014) A mathematical model of cellular metabolism during ischemic stroke and hypothermia. IEEE Trans Biomed Eng 61(2):484-490

16. Kaynezhad P, Mitra S, Bale G, Bauer C, Lingam I, Meehan C, Avdic-Belltheus A, Martinello K, Bainbridge A, Robertson NJ, Tachtsidis I (2019) Quantification of the severity of hypoxic ischemic brain injury in a neonatal preclinical model using miniature broadband-NIRS measurements of cytochrome-c-oxidase. Neurophotonics 6(4):045009

17. Russell-Buckland J, Barnes CP, Tachtsidis I (2019) A Bayesian framework for the analysis of systems biology models of the brain. PLoS Comput Biol 15(4):e1006631 
Open Access This chapter is licensed under the terms of the Creative Commons Attribution 4.0 International License (http://creativecommons.org/licenses/by/4.0/), which permits use, sharing, adaptation, distribution and reproduction in any medium or format, as long as you give appropriate credit to the original author(s) and the source, provide a link to the Creative Commons license and indicate if changes were made.

The images or other third party material in this chapter are included in the chapter's Creative Commons license, unless indicated otherwise in a credit line to the material. If material is not included in the chapter's Creative Commons license and your intended use is not permitted by statutory regulation or exceeds the permitted use, you will need to obtain permission directly from the copyright holder.

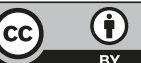

